\title{
Increasing Sexually Transmitted Infections in the U.S.: A Call for Action for Research, Clinical, and Public Health Practice
}

\author{
Lori A. J. Scott-Sheldon ${ }^{1,2,3} \cdot$ Philip A. Chan ${ }^{3,4}$
}

Published online: 13 November 2019

(c) Springer Science+Business Media, LLC, part of Springer Nature 2019

As recently reported in the New York Times (Stack, 2019), sexually transmitted infections (STIs), including chlamydia, gonorrhea, and syphilis diagnoses, continue to rise in the U.S. despite current public health efforts. Rates of chlamydia have reached an all-time high with 1.8 million cases in 2018 (Centers for Disease Control and Prevention, 2019c) (Fig. 1). Gonorrhea and syphilis infections have also increased 39\% and 42\%, respectively, from 2014 to 2018 (Figs. 2, 3). Women, adolescents and young adults, and gay, bisexual, and other men who have sex with men (MSM) continue to bear a disproportionate burden of STIs. Sixtyfive percent of chlamydia cases were reported in women, and of all reported cases of chlamydia among women, $68 \%$ were among young women 15-24 years of age. Rates of chlamydia are lower in men compared to women, likely due to screening recommendations for women, but diagnoses increased 38\% from 2014 to 2018 in men. Rates of gonorrhea have increased $79 \%$ among men and $45 \%$ among women from 2014 to 2018 . The increased rates among men may reflect screening recommendations for MSM (Table 1). Gonorrhea rates continue to be the highest among young adults 20-24 years of age (702.6 and 720.0 out per 100,000 cases of women and men, respectively). Men accounted for

Lori A. J. Scott-Sheldon

lori_scott-sheldon@brown.edu

1 Centers for Behavioral and Preventive Medicine, The Miriam Hospital, CORO West, Suite 309, 164 Summit Ave, Providence, RI 02906, USA

2 Department of Psychiatry and Human Behavior, Alpert Medical School, Brown University, Providence, RI, USA

3 Department of Behavioral and Social Sciences, Brown School of Public Health, Providence, RI, USA

4 Department of Medicine, Alpert Medical School, Brown University, Providence, RI, USA
$86 \%$ of all primary and secondary syphilis cases with $54 \%$ reported among MSM.

There are multiple reasons for the ongoing increases in the number of cases of STIs. One possible reason is that more people are being tested, resulting in an increase in reported cases. For some populations (e.g., sexually active young women, MSM), more frequent testing may be driving the increases in reported cases to the CDC. Recent trends also suggest that changing sexual behaviors may be contributing to these increases. While the number of U.S. adolescents and adults currently having sex has decreased over the past two decades (Centers for Disease Control and Prevention, 2019a; Smith, Davern, Freese, \& Morgan, 2019), riskier sexual behaviors are on the rise. For example, data from the Youth Risk Behavioral Survey demonstrate that condom use during the last sex event decreased among 9th through 12th grade students from a peak of 63\% in 2003 to 54\% in 2017 (Kann et al., 2018). During this same time period, oral contraception also increased from 17 to $21 \%$ in this group which may have had an impact on condom use (Kann et al., 2018). Data from the National Survey of Family Growth found mixed results: Condom use at last sex remained unchanged among women (23-24\%) but increased in men (30-36\%) from 2002 to 2017 (Centers for Disease Control and Prevention, 2019b).

Condom use rates may be influenced by a decreasing concern about HIV given advances in treatment and prevention, including the HIV Undetectable $=$ Untransmittable $(\mathrm{U}=\mathrm{U})$ initiative (Eisinger, Dieffenbach, \& Fauci, 2019). Furthermore, increased rates of primary and secondary syphilis among MSM are a growing concern because it is associated with HIV transmission (Kidd, Torrone, Su, \& Weinstock, 2018) and approximately $36 \%$ of primary and secondary syphilis cases in 2017 were among MSM who are HIV positive (Centers for Disease Control and Prevention, 2019c). Importantly, approximately $10 \%$ of all new HIV infections may be attributed to gonorrhea and chlamydia infections (Jones, Sullivan, \& Curran, 2019). Significant increases in STIs have also been observed among MSM taking pre-exposure prophylaxis (PrEP) for HIV 
Fig. 1 Chlamydia cases among adults $15-54$ years of age by sex, 2000-2018. Note. Data obtained from the National Center for HIV/AIDS, Viral Hepatitis, STD, and TB Prevention (NCHHSTP) AtlasPlus (Centers for Disease Control 2018 CDC Surveillance Report (Centers for Disease Control and Prevention, 2019c). NAAT nucleic acid amplification test. PrEP pre-exposure prophylaxis and Prevention, 2017) and the

Fig. 2 Gonorrhea cases among adults $15-54$ years of age by sex, 2000-2018. Note. Data obtained from the NCHHSTP AtlasPlus (Centers for Disease Control and Prevention, 2017) and the 2018 CDC Surveillance Report (Centers for Disease Control and Prevention, 2019c). NAAT nucleic acid amplification test. $\operatorname{PrEP}$ pre-exposure prophylaxis
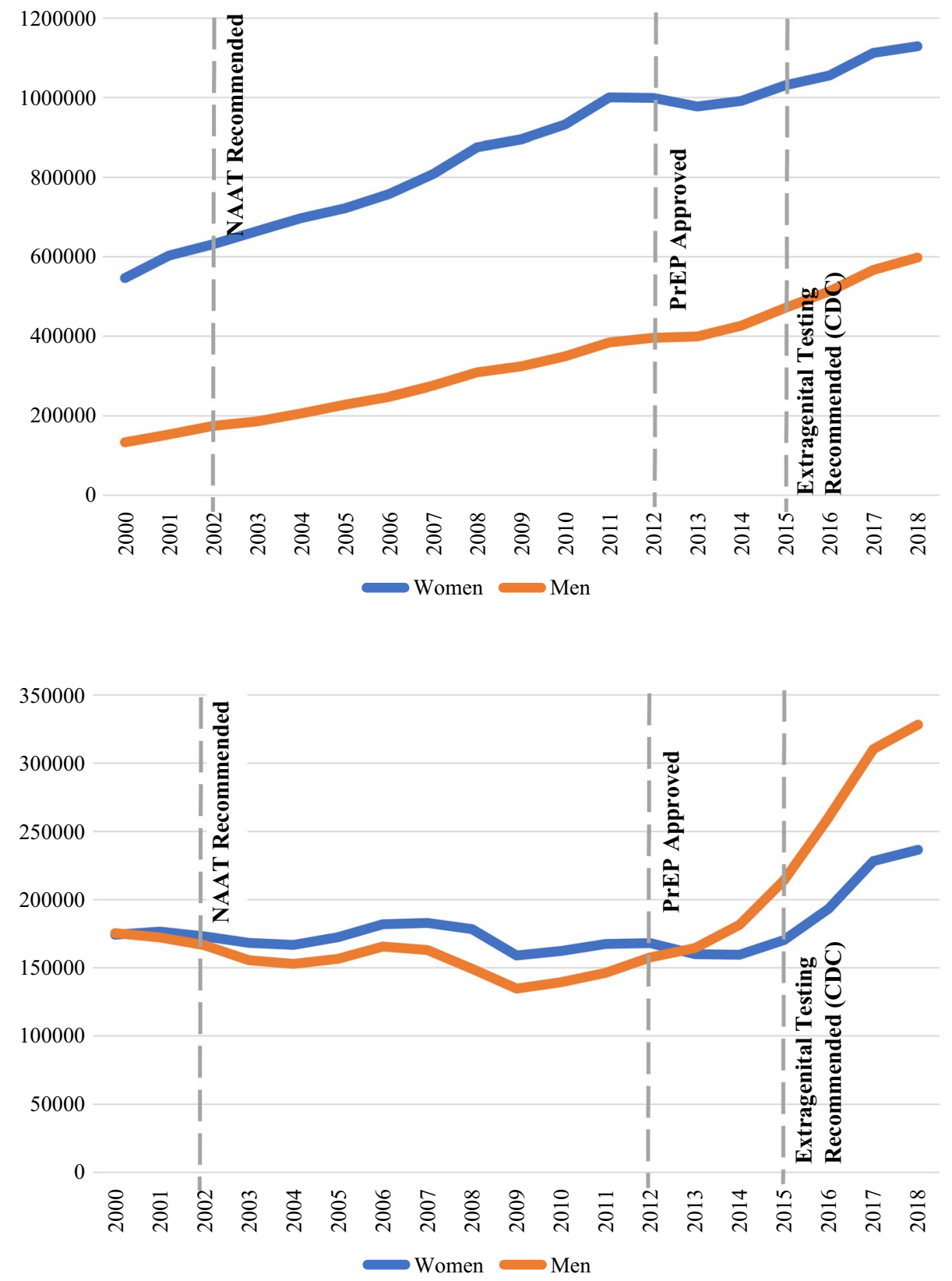

prevention (Montano et al., 2019). Although the total number of partners may be unchanged, MSM on PrEP may use condoms less, increasing the risk of acquiring STIs (Oldenburg et al., 2018). Increases, however, may reflect more frequent screening for STIs among men taking PrEP (Montano et al., 2019). MSM taking PrEP should be screened for other STIs every 3 months (Centers for Disease Control and Prevention, 2015), which would be much more frequent than observed among MSM not on PrEP (Hoots, Torrone, Bernstein, \& PazBailey, 2018). This may contribute, in part, to the observed increases in STIs in this population.

To address the burden of STIs, the U.S. must address healthcare access. Multiple individual, interpersonal, community, and societal factors may impact access to health care, including appropriate STI screening, diagnoses, and treatment. The most common barriers to STI testing include lack of access to clinical services, out-of-pocket costs for both uninsured and underinsured, confidentiality concerns, and stigma associated with testing (Montgomery et al., 2017). These barriers may be more pronounced in racial and ethnic minorities with rates of chlamydia and gonorrhea highest in Black/African Americans in 2018. Furthermore, rates of reported syphilis increased $78 \%$ from 2014 to 2018 among Hispanic/Latinos. State and federal budget cuts to STI programs (e.g., STI clinics) have a direct impact on access 
Fig. 3 Primary and secondary syphilis cases among adults $15-54$ years of age by sex, 2000-2018. Note. Data obtained from the NCHHSTP AtlasPlus (Centers for Disease Control and Prevention, 2017) and the 2018 CDC Surveillance Report (Centers for Disease Control and Prevention, 2019c). NAAT nucleic acid amplification test. $\operatorname{PrEP}$ pre-exposure prophylaxis

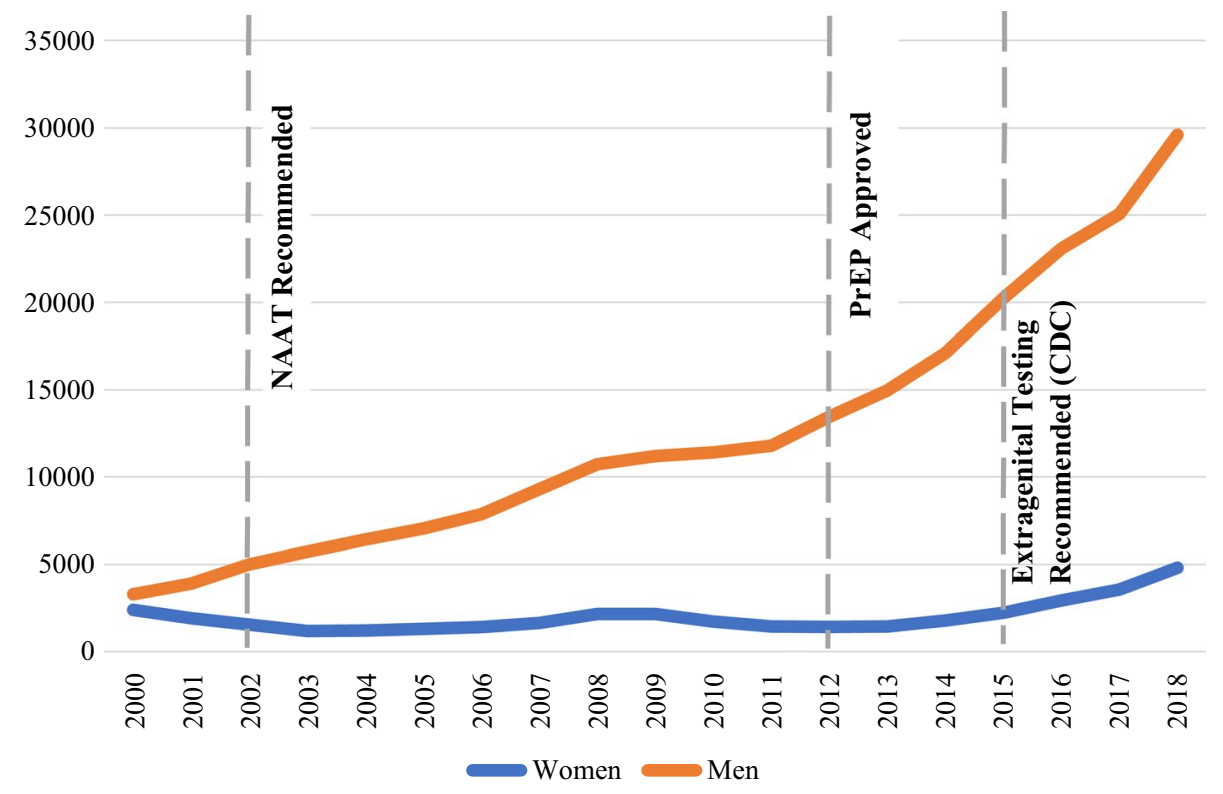

Table 1 Centers for Disease Control and Prevention screening recommendations for sexually transmitted infections (Centers for Disease Control and Prevention, 2015)

\begin{tabular}{|c|c|}
\hline Population & Recommendation \\
\hline Women & $\begin{array}{l}\text { Chlamydia: sexually active women }<25 \text { years old and } \geq 25 \text { years old if at increased risk. Among pregnant women }<25 \text { years } \\
\text { of age, retest in third trimester if at increased risk } \\
\text { Gonorrhea: sexually active women }<25 \text { years old and } \geq 25 \text { years old if at increased risk } \\
\text { Syphilis: all pregnant women at first prenatal visit; retest third trimester and at delivery if at increased risk }\end{array}$ \\
\hline Heterosexual men & Chlamydia/gonorrhea/syphilis: consider screening men in high-prevalence settings or in certain populations \\
\hline MSM & $\begin{array}{l}\text { Chlamydia/gonorrhea/syphilis: at least annually and every 3-6 months if at increased risk. Includes extragenital testing for } \\
\text { gonorrhea and chlamydia }\end{array}$ \\
\hline Persons with HIV & $\begin{array}{l}\text { Chlamydia/gonorrhea/syphilis: at initial HIV evaluation and annually thereafter. More frequent screening for individuals at } \\
\text { risk }\end{array}$ \\
\hline \multicolumn{2}{|c|}{ Pre-exposure prophylaxis patients } \\
\hline Women & Chlamydia/gonorrhea/syphilis: every 3-6 months \\
\hline Heterosexual men & Chlamydia/gonorrhea/syphilis: every 3-6 months \\
\hline MSM & Chlamydia/gonorrhea/syphilis: every 3 months \\
\hline
\end{tabular}

to these services, especially in safety-net settings and among racial and ethnic minority groups.

Addressing the STI epidemic will require a combined approach to improve routine testing and treatment in primary care settings, as well as in safety-net settings (i.e., STI clinics). The CDC and United States Preventative Services Task Force recommend routine testing for people at risk of STIs (Table 1). The primary care workforce is essential to engage in STI prevention efforts which should include routine testing in at-risk populations. Quality measures such as the Healthcare Effectiveness Data and Information Set demonstrate that in the case of chlamydia, only $47 \%$ of sexually active women less than 25 years have been screened despite recommendations (Khosropour et al., 2014). Sexual history taking is often not performed with less than one-third of primary care providers reporting taking a sexual history at their last patient visit (St Lawrence et al., 2002). Men who report same-sex behaviors are often not identified, screened appropriately for STIs, and offered appropriate preventative care (i.e., PrEP) (Scott \& Klausner, 2016). Safety-net settings in the form of STI clinics are also important for marginalized populations who are at risk and may not have access to primary care, including MSM. STI clinics also often serve as important referral sites for complicated cases, as well as centers for education and training in the community. 
Screening for gonorrhea and chlamydia should also include throat and rectal swabs in MSM (extragenital testing) to access infection at these sites (Centers for Disease Control and Prevention, 2014). Extragenital screening among MSM showed that $>70 \%$ of chlamydia and $>80 \%$ of gonorrhea infections would have been missed with urine testing alone (Anschuetz, Paulukonis, Powers, \& Asbel, 2016). Testing in women is currently not recommended, although approximately $14 \%$ of chlamydia and $30 \%$ of gonorrhea infections among women may be missed with urine-only testing (Trebach, Chaulk, Page, Tuddenham, \& Ghanem, 2015). Chlamydia and gonorrhea infections at extragenital sites are often asymptomatic in men and women (Bamberger, Graham, Dennis, \& Gerkovich, 2019; Chan et al., 2016). Culture detection is available for testing at extragenital sites, but the nucleic acid amplification test (NAAT) is more sensitive than cell cultures and is the preferred method for laboratory detection of chlamydia and gonorrhea. Extragenital screening using NAAT is available at many local, state, and commercial laboratories and is approved by the Food and Drug Administration (Centers for Disease Control and Prevention, 2009; Johnson Jones et al., 2019; U.S. Food and Drug Administration, 2019).

Important gaps in research also exist, which may hinder efforts to effectively address rising rates in STIs. Screening for gonorrhea and chlamydia in cis-gender, heterosexual men is not recommended due to lack of evidence of a populationlevel benefit although it stands to reason that most women are acquiring these infections from sex with men. Extragenital testing is also not recommended in cis-gender, heterosexual men and women given lack of benefit of extragenital screening on potential sequelae. Extragenital infections in heterosexual men and women do occur (Chan et al., 2016), and there is evidence that infection at extragenital sites can be transmitted to the urogenital tract (den Heijer et al., 2017). Importantly, future research efforts should identify systematic efforts to improve screening and early diagnoses and treatment efforts. These may include specific quality measures by insurers, which include financial incentives to promote screening among primary care providers and others.

In conclusion, STI cases continue to rise across the U.S. which likely reflects more sensitive screening and detection methods as well as increased sexual risk behaviors. Increased screening, diagnoses, and treatment of STIs-including asymptomatic infections-will be important to reduce the overall prevalence. Further reductions in the incidence of STIs will require the promotion of sexual health among all people with focused efforts on women, adolescents and young adults, and MSM who continue to bear a disproportionate burden of STIs. Finally, future efforts are needed to effectively address these increases across research, clinical, and public health practice.

\section{References}

Anschuetz, G. L., Paulukonis, E., Powers, R., \& Asbel, L. E. (2016). Extragenital screening in men who have sex with men diagnoses more chlamydia and gonorrhea cases than urine testing alone. Sexually Transmitted Diseases, 43(5), 299-301. https://doi. org/10.1097/OLQ.0000000000000435.

Bamberger, D. M., Graham, G., Dennis, L., \& Gerkovich, M. M. (2019). Extragenital gonorrhea and chlamydia among men and women according to type of sexual exposure. Sexually Transmitted Diseases, 46(5), 329-334. https://doi.org/10.1097/olq.0000000000 000967.

Centers for Disease Control and Prevention. (2009). Clinic-based testing for rectal and pharyngeal Neisseria gonorrhoeae and Chlamydia trachomatis infections by community-based organizations-five cities, United States, 2007. Morbidity and Mortality Weekly Report, 58(26), 716-719.

Centers for Disease Control and Prevention. (2014). Recommendations for the laboratory-based detection of Chlamydia trachomatis and Neisseria gonorrhoeae-2014. Morbidity and Mortality Weekly Reports, 63(RR-02), 1-19.

Centers for Disease Control and Prevention. (2015). Sexually transmitted diseases treatment guidelines, 2015. Morbidity and Mortality Weekly Report, 64(RR-03), 1-137.

Centers for Disease Control and Prevention. (2017). National Center for HIV/AIDS, Viral Hepatitis, STD, and TB Prevention (NCHHSTP) AtlasPlus. Retrieved October 20, 2019, from https://www.cdc.gov/ nchhstp/atlas/index.htm.

Centers for Disease Control and Prevention. (2019a). 1991-2017 high school youth risk behavior survey data. Retrieved November 3, 2019, from http://nccd.cdc.gov/youthonline/.

Centers for Disease Control and Prevention. (2019b). National survey of family growth, 2002-2018. Retrieved October 20, 2019, from https://www.cdc.gov/nchs/nsfg/index.htm.

Centers for Disease Control and Prevention. (2019c). Sexually transmitted disease surveillance 2018. Retrieved October 18, 2019, from https://www.cdc.gov/std/stats18/STDSurveillance2018-full-repor t.pdf.

Chan, P. A., Robinette, A., Montgomery, M., Almonte, A., Cu-Uvin, S., Lonks, J. R., \& Hardy, E. J. (2016). Extragenital infections caused by chlamydia trachomatis and neisseria gonorrhoeae: A review of the literature. Infectious Diseases in Obstetrics and Gynecology. https://doi.org/10.1155/2016/5758387.

den Heijer, C. D. J., Hoebe, C., van Liere, G., van Bergen, J., Cals, J. W. L., Stals, F. S., \& Dukers-Muijrers, N. (2017). A comprehensive overview of urogenital, anorectal and oropharyngeal Neisseria gonorrhoeae testing and diagnoses among different STI care providers: A cross-sectional study. BMC Infectious Diseases, 17(1), 290. https://doi.org/10.1186/s12879-017-2402-0.

Eisinger, R. W., Dieffenbach, C. W., \& Fauci, A. S. (2019). HIV viral load and transmissibility of HIV infection: Undetectable equals untransmittable. Journal of the American Medical Association, 321(5), 451-452. https://doi.org/10.1001/jama.2018.21167.

Hoots, B. E., Torrone, E. A., Bernstein, K. T., \& Paz-Bailey, G. (2018). Self-reported chlamydia and gonorrhea testing and diagnosis among men who have sex with men-20 US cities, 2011 and 2014. Sexually Transmitted Diseases, 45(7), 469-475. https://doi. org/10.1097/olq.0000000000000786.

Johnson Jones, M. L., Chapin-Bardales, J., Bizune, D., Papp, J. R., Phillips, C., Kirkcaldy, R. D., \& Bernstein, K. T. (2019). Extragenital chlamydia and gonorrhea among community venue-attending men who have sex with men-five cities, United States, 2017. Morbidity and Mortality Weekly Report, 68(14), 321-325. https://doi. org/10.15585/mmwr.mm6814a1. 
Jones, J., Sullivan, P. S., \& Curran, J. W. (2019). Progress in the HIV epidemic: Identifying goals and measuring success. PLoS Medcine, 16(1), e1002729. https://doi.org/10.1371/journal.pmed.1002729.

Kann, L., McManus, T., Harris, W. A., Shanklin, S. L., Flint, K. H., Queen, B., \& Ethier, K. A. (2018). Youth Risk Behavior Surveillance-United States, 2017. Morbidity and Mortality Weekly Report, 67(8), 1-114. https://doi.org/10.15585/mmwr.ss6708a1.

Khosropour, C. M., Broad, J. M., Scholes, D., Saint-Johnson, J., Manhart, L. E., \& Golden, M. R. (2014). Estimating chlamydia screening coverage: A comparison of self-report and health care effectiveness data and information set measures. Sexually Transmitted Diseases, 41(11), 665-670. https://doi.org/10.1097/OLQ.00000 00000000186.

Kidd, S., Torrone, E., Su, J., \& Weinstock, H. (2018). Reported primary and secondary syphilis cases in the United States: Implications for HIV infection. Sexually Transmitted Diseases, 45(9S Suppl. 1), S42-S47. https://doi.org/10.1097/olq.0000000000000810.

Montano, M. A., Dombrowski, J. C., Dasgupta, S., Golden, M. R., Duerr, A., Manhart, L. E., \& Khosropour, C. M. (2019). Changes in sexual behavior and STI diagnoses among MSM initiating PrEP in a clinic setting. AIDS and Behavior, 23(2), 548-555. https://doi. org/10.1007/s10461-018-2252-9.

Montgomery, M. C., Raifman, J., Nunn, A. S., Bertrand, T., Uvin, A. Z., Marak, T., \& Chan, P. A. (2017). Insurance coverage and utilization at a sexually transmitted disease clinic in a medicaid expansion state. Sexually Transmitted Diseases, 44(5), 313-317. https://doi. org/10.1097/OLQ.0000000000000585.

Oldenburg, C. E., Nunn, A. S., Montgomery, M., Almonte, A., Mena, L., Patel, R. R., \& Chan, P. A. (2018). Behavioral changes following uptake of HIV pre-exposure prophylaxis among men who have sex with men in a clinical setting. AIDS and Behavior, 22(4), 1075-1079. https://doi.org/10.1007/s10461-017-1701-1.

Scott, H. M., \& Klausner, J. D. (2016). Sexually transmitted infections and pre-exposure prophylaxis: Challenges and opportunities among men who have sex with men in the US. AIDS Research and Therapy, 13(1), 5. https://doi.org/10.1186/s12981-016-0089-8.

Smith, T. W., Davern, M., Freese, J., \& Morgan, S. (2019). General social surveys, 1972-2018. Retrieved October 20, 2019, from https ://gssdataexplorer.norc.org/.

St Lawrence, J. S., Montano, D. E., Kasprzyk, D., Phillips, W. R., Armstrong, K., \& Leichliter, J. S. (2002). STD screening, testing, case reporting, and clinical and partner notification practices: A national survey of US physicians. American Journal of Public Health, 92(11), 1784-1788. https://doi.org/10.2105/ajph.92.11.1784.

Stack, L. (2019). Sexually transmitted disease cases rise to record high, C.D.C. says. New York Times. Retrieved October 9, 2019, from https://www.nytimes.com/2019/10/08/health/cdc-std-study.html.

Trebach, J. D., Chaulk, C. P., Page, K. R., Tuddenham, S., \& Ghanem, K. G. (2015). Neisseria gonorrhoeae and chlamydia trachomatis among women reporting extragenital exposures. Sexually Trasmitted Diseases, 42(5), 233-239. https://doi.org/10.1097/OLQ.00000 00000000248.

U.S. Food and Drug Administration. (2019). FDA clears first diagnostic tests for extragenital testing for chlamydia and gonorrhea [Press release]. Retrieved October 17, 2019, from https://www.fda.gov/ news-events/press-announcements/fda-clears-first-diagnostic-tests -extragenital-testing-chlamydia-and-gonorrhea.

Publisher's Note Springer Nature remains neutral with regard to jurisdictional claims in published maps and institutional affiliations. 